\section{Cotyledonary Axillary Shoot Control by Fatty Alcohol Application for Grafting Tomato}

\author{
Tomomi Eguchi and Chieri Kubota ${ }^{1}$
}

\begin{abstract}
ADDITIONAL INDEX WORDS. sucker control, chemical control, axillary buds, meristems, Solanum lycopersicum

SUMmary. In tomato (Solanum lycopersicum), grafting position is recommended to be below rootstock cotyledons to avoid undesirable axillary shoots growing out from the cotyledons. In contrast, grafting above the rootstock cotyledons is desired to assure adequate distance between grafted union and soil line, only if there is no potential grow-out of axillary shoots from rootstock cotyledons. The objective of this preliminary study was to examine fatty alcohol application on cotyledonary axils of tomato seedlings to control undesirable axillary shoot extension from rootstock in tomato grafting. Solution containing various concentrations of a commercial fatty alcohol compound was applied to different growing stages of cotyledonary axillary shoots (nonextended buds or extended shoots) of tomato seedlings grown in a greenhouse. When fatty alcohol was applied directly to cotyledonary axillary buds, the seedlings were then pinched to force-induce the axillary shoot extension to assure the efficacy of the fatty alcohol treatment. High concentrations $(10 \%$ and $15 \%)$ of fatty alcohol suppressed incidence of axillary shoot extension to less than $7 \%$ by killing buds. However, when applied to extended axillary shoots, application with $\mathbf{2 \%}$ or higher concentrations of fatty alcohol caused plant collapse because excess fatty alcohol flowed down the stem and presumably damaged the root system. Therefore, we concluded that application of fatty alcohol to control cotyledonary axillary shoots of tomato rootstock could be possible only if fatty alcohol at effective concentration (10\% to $15 \%)$ is applied exclusively to the target buds.
\end{abstract}

$S$ ince use of methyl bromide for soil fumigation has been limited by the Montreal Protocol, there is an increasing need to find an alternative method to manage soilborne pathogens and pests in open-field vegetable production. One of the proposed alternative methods is the use of grafting rootstock that is resistant to soilborne diseases (Kubota et al., 2008). Although vegetable grafting has been widely used in Asia and Europe to manage soilborne diseases, the use is still limited in the United States (Lee et al., 2010; Louws et al., 2010). One issue limiting the use is the large number of seedlings needed for large-scale open-field production, and another issue is the high cost of grafted seedlings compared with conventional seeds or seedlings. However, vegetable grafting as an alternative to soil fumigation with methyl bromide is now

\footnotetext{
School of Plant Sciences, The University of Arizona, Tucson, AZ 85721-0036

This project was funded by USDA NIFA SCRI (Award Number 2011-51181-30963). The authors would like to thank Richard Hassell and Shawana Daley at Clemson University for providing technical consultation. The authors also thank Fair Products, Inc. (Cary, NC) for providing N-TAC for our experimental use.

${ }^{1}$ Corresponding author. E-mail: ckubota@e-mail.
} arizona.edu. attracting growing interest in the United States (Colla, 2010).

In vegetable grafting, the position of the grafted union must be high enough to prevent the vulnerable scion from coming into direct contact and exposure with the soil, especially when the grafted plants are transplanted by machines in large-scale open-field production. For tomato, while grafting above the rootstock cotyledons could be a solution to assure adequate distance between grafted union and soil line, potential grow-out of axillary shoots from rootstock cotyledons can be problematic because it requires additional labor cost to manually prune the axillary shoots in the field as well as at the propagation stage (Bausher, 2011). Therefore, the use of chemicals to inhibit the cotyledonary axillary shoot growth from rootstock may allow grafting above cotyledons and reduce the additional management cost of grafted tomato production in the field.

Fatty alcohol and fatty acid methyl ester with carbon chain lengths from 8 to 12 , emulsified with appropriate surfactants, have been reported to kill the rapidly dividing meristematic tissues such as apical and axillary buds without damaging mature leaf or stem tissues in a variety of plants (Cathey et al., 1966; Steffens et al., 1967; Tso, 1964; Tso et al., 1965). The mechanism of selective killing of the meristematic tissue in tobacco (Nicotiana tabacum) is reportedly due to the property of the well-developed cuticular layer over mature tissue that acts a penetration barrier to these chemicals compared with young tissue (Nelson and Reid, 1971). Once penetrating the meristematic tissue, these chemicals disrupt the plasma membranes and cause desiccation of the tissue (Wheeler et al., 1991). In tobacco production, commercially available fatty alcohols, usually mixtures of octanol $\left(\mathrm{C}_{8}\right.$ fatty alcohol $)$, decanol $\left(\mathrm{C}_{10}\right.$ fatty alcohol), and sometimes dodecanol $\left(\mathrm{C}_{12}\right.$ fatty alcohol $)$ formulated with surfactants, have been used to control axillary shoot (sucker) growth after topping (removal of the flower heads) (Steffens, 1980). Topping and sucker control of tobacco improves yield and the concentration of nicotine of leaf to be harvested, by reducing the competition of nutrients (Moore, 2012). Also a commercial fatty alcohol compound used on tobacco was recently demonstrated to be a part of new grafting method for watermelon (Citrullus lanatus), controlling rootstock shoot regrowth while preparing seedlings (Daley, 2014; Daley and Hassell, 2014). For tomato, Maw (1977) demonstrated effective use of fatty alcohol for controlling axillary shoot on tomato plants grown in greenhouse, although the fatty alcohol had to be applied exclusively to the axillary shoots otherwise it caused chemical damage on leaves and stems. These studies suggest that fatty alcohol could control growth of cotyledonary axillary shoot for tomato

\begin{tabular}{llll}
\hline $\begin{array}{l}\text { Units } \\
\text { To convert U.S. to SI, } \\
\text { multiply by }\end{array}$ & U.S. unit & SI unit & $\begin{array}{l}\text { To convert SI to U.S., } \\
\text { multiply by }\end{array}$ \\
\hline 29,574 & $\mathrm{fl} \mathrm{oz}$ & $\mu \mathrm{L}$ & $3.3814 \times 10^{-5}$ \\
2.54 & inch $(\mathrm{es})$ & $\mathrm{cm}$ & 0.3937 \\
1 & $\mathrm{mmho} / \mathrm{cm}$ & $\mathrm{dS} \cdot \mathrm{m}^{-1}$ & 1 \\
1 & $\mathrm{ppm}$ & $\mathrm{mg} \cdot \mathrm{L}^{-1}$ & 1 \\
$\left({ }^{\circ} \mathrm{F}-32\right) \div 1.8$ & ${ }^{\circ} \mathrm{F}$ & ${ }^{\circ} \mathrm{C}$ & $\left({ }^{\circ} \mathrm{C} \times 1.8\right)+32$
\end{tabular}

Hortechology $\cdot$ August $201525(4)$ 
rootstocks; however, there is no information on the effective concentration and application methods of fatty alcohol for young tomato or tomato rootstock seedlings of 2 to 3 weeks after germination.

The objective of this preliminary study was to determine the effects of fatty alcohol applied at various concentrations on cotyledonary axils (nonextended buds or extended shoots) and possible chemical damage of tomato seedlings, to evaluate the possibility of using fatty alcohol to control cotyledonary axillary shoot from rootstock in tomato grafting.

\section{Materials and methods}

Plant materials and growth CONDITIONS. 'Roma VF' tomato (Westar Seeds International, El Centro, CA) was used in this study. 'Roma VF' is not a commercial rootstock but we employed this cultivar for our study as a model system because of the abundant availability of seeds. Seeds were sown into 98 -cell seedling trays $(28 \times$ $55 \mathrm{~cm}$, one seed per cell) filled with moist commercial substrate (Sunshine Professional Mix 3; Sun Gro Horticulture, Agawam, MA) covered with a thin layer of vermiculite. The seeded trays were then covered with a thin plastic film and placed for $2 \mathrm{~d}$ under darkness in a growth chamber (model 2015; VWR International, Radnor, PA) controlled at $29 \pm 1{ }^{\circ} \mathrm{C}$ air temperature. Two days after seeding, the trays were placed in the greenhouse and irrigated every $2 \mathrm{~d}$ with tap water. After day 11 , the plants were irrigated daily with tap water and twice weekly with nutrient solution (EC 2.0 to $2.4 \mathrm{dS} \cdot \mathrm{m}^{-1}$, $\mathrm{pH} 5.9$ to 6.3 ) containing $90 \mathrm{mg} \cdot \mathrm{L}^{-1}$ nitrogen (all in nitrate form), $47 \mathrm{mg} \cdot \mathrm{L}^{-1}$ phosphorus, $144 \mathrm{mg} \cdot \mathrm{L}^{-1}$ potassium, 160 $\mathrm{mg} \cdot \mathrm{L}^{-1}$ calcium, $60 \mathrm{mg} \cdot \mathrm{L}^{-1}$ magnesium, and $113 \mathrm{mg} \cdot \mathrm{L}^{-1}$ sulfur, as well as micronutrients. The greenhouse used in the present experiments was located in Tucson, AZ, covered by double-layered acrylic roof and walls, and equipped with pad-and-fan cooling and overhead gas heating systems. The daytime and nighttime set points of air temperature were 28 and $21^{\circ} \mathrm{C}$, respectively, using a commercial greenhouse controller (Wadsworth Control Systems, Arvada, CO). After 17 or $18 \mathrm{~d}$ from seeding, when seedlings were at the three-true-leaf stage, uniform seedlings were selected for the experiments.
FATTy AlCOHOL. A commercially available fatty alcohol compound $\left(\mathrm{N}^{-T A C}{ }^{\circledR}\right.$; Fair Products, Cary, NC), consisting of $36.2 \% \mathrm{C}_{8}, 48.2 \% \mathrm{C}_{10}$, $0.3 \% \mathrm{C}_{12}$ fatty alcohol, and $15.3 \%$ other ingredients, was used in this study. Fatty alcohol was diluted with ion-exchanged water to prepare emulsions having product concentrations from $0.5 \%$ to $15 \%(\mathrm{v} / \mathrm{v})$ for the experiments described below.

FATTY ALCOHOL TREATMENT TO AXILLARY BUDS (EXPT. 1). Seventeen days after seeding (5 May 2014), plants were treated with $0 \%, 2 \%, 5 \%$, $10 \%$, or $15 \%(\mathrm{v} / \mathrm{v})$ concentration of fatty alcohol emulsions. Using a pipette, $5 \mu \mathrm{L}$ of the emulsion was applied carefully to each cotyledonary axil area of all the seedlings. The application volume was selected so that it thoroughly covers the axillary bud without overflowing to contact the stem. To assess the effectiveness of the fatty alcohol treatment, plants were pinched about $1 \mathrm{~cm}$ above cotyledons $\mathrm{l} \mathrm{d}$ after the treatment to force undamaged axillary buds to develop shoots. Plants were visually inspected for any sign of chemical damage or axillary shoot extension 1 , 7, 14, and $22 \mathrm{~d}$ after treatment. Because the incidence of axillary shoot extension became unchanged after day 14 , we conducted the inspection up to day 22. To examine the degree of damage to the axillary buds caused by fatty alcohol treatment, the axillary buds of three to five representative plants per treatment were observed under stereomicroscope (Vista Vision, VWR International).

FATTY ALCOHOL TREATMENT TO EXTENDED AXILLARY SHOOTS (EXPT. 2). Eighteen days after seeding (6 May 2014), plants were pinched about $1 \mathrm{~cm}$ above cotyledons to force cotyledonary axillary shoots to develop. Seven days after pinching, axillary shoots in length from 1.8 to $3.2 \mathrm{~cm}$ were treated with $0 \%$, $0.5 \%, 1 \%, 2 \%, 4 \%$, or $5 \%(\mathrm{v} / \mathrm{v})$ concentration of fatty alcohol emulsions. These concentrations examined in this experiment were selected based on the phytotoxicity observed in Expt. 1. Using a pipette, $250 \mu \mathrm{L}$ of the emulsion was applied to each axillary shoot. The application volume was selected so that the axillary shoot was covered thoroughly with emulsion. Plants were visually inspected for any sign of chemical damage and axillary shoot growth $1,7,15$, and $2 \mathrm{l} \mathrm{d}$ after treatment.
EXPERIMENTAL DESIGN. The study was conducted from 18 Apr. to 3 June 2014. For both experiments (Expt. 1 and 2), each treatment consisted of 10 plants and the treatments were repeated three times using a seedling tray (98 cells) as a replication. Five (Expt. 1) and 6 treatments (Expt. 2) of different fatty alcohol concentrations were randomly assigned within each seedling tray. Positions of three trays over the bench inside the greenhouse were rotated systematically every day to improve the uniformity of environments. JMP Pro (version 9.0; SAS Institute, Cary, NC) was used to analyze data. Percent data were arcsine-transformed and their means were separated by Tukey's honest significant difference test at $P \leq 0.05$.

\section{Results and discussion}

Greenhouse environments. Average day/night air temperatures in the greenhouse were $24.6 \pm 2.4$ / $18.5 \pm 2.1^{\circ} \mathrm{C}$ in Expt. 1 and $25.2 \pm$ $2.7 / 19.0 \pm 2.4^{\circ} \mathrm{C}$ in Expt. 2. Average DLIs in the greenhouse were estimated from the solar radiation recorded in the weather station (The University of Arizona, 2014) and the predetermined greenhouse light transmission of $42 \%: 25.2 \pm 2.6 \mathrm{~mol} \cdot \mathrm{m}^{-2} \cdot \mathrm{d}^{-1}$ in Expt. 1 and $25.0 \pm 3.2 \mathrm{~mol} \cdot \mathrm{m}^{-2} \cdot \mathrm{d}^{-1}$ in Expt. 2.

Expт. 1. Seven days after fatty alcohol treatment, the control plants (treated with $0 \%$ fatty alcohol) had $100 \%$ of plants with axillary shoot extension, induced by pinching $(\mathrm{Ta}-$ ble 1 ; Fig. lA). At 2\%, $5 \%$, and $10 \%$ concentrations, the percentage of plants with axillary shoot extension increased over the first $14 \mathrm{~d}$ but remained the same after day 14 (Table 1). Twenty-two days after fatty alcohol treatment, the percentage of plants with axillary shoot extension at $2 \%$ fatty alcohol concentration was nonsignificantly different from that in the control. The percentage of plants with axillary shoot extension at $5 \%$ was significantly lower than that in the control but at an unacceptable level (23.3\%). The high concentrations (10\% and 15\%) of fatty alcohol treatment significantly suppressed the percentage of plants with axillary shoot extension to below $7 \%$ throughout the experiment (Table 1). Under the stereomicroscope, the plants with no axillary shoot 
Table 1. Effects of fatty alcohol at various concentrations applied to cotyledonary axillary buds in pinched tomato seedling on the resulting percentage of plants with cotyledonary axillary shoot extension $(7,14$, or $22 \mathrm{~d}$ after treatment) and the percentage of plants with chemical damage ( $22 \mathrm{~d}$ after treatment) (Expt. 1$)$.

\begin{tabular}{|c|c|c|c|c|c|}
\hline \multirow{2}{*}{$\begin{array}{l}\text { Fatty alcohol concn } \\
(\%)\end{array}$} & \multicolumn{3}{|c|}{ Axillary shoot extension $(\%)^{\mathrm{z}}$} & \multicolumn{2}{|c|}{ Chemical damage $(\%)^{\mathrm{z}}$} \\
\hline & $7 \mathrm{~d}$ & $14 \mathrm{~d}$ & $22 \mathrm{~d}$ & Stem scarring & Cotyledon damage \\
\hline 0 (control) & $100.0 \mathrm{a}^{\mathrm{y}}$ & $100.0 \mathrm{a}$ & $100.0 \mathrm{a}$ & $0.0 \mathrm{~d}$ & $0.0 \mathrm{c}$ \\
\hline 5 & $10.0 \mathrm{bc}$ & $23.3 \mathrm{bc}$ & $23.3 \mathrm{bc}$ & $76.7 \mathrm{~b}$ & $10.0 \mathrm{bc}$ \\
\hline 10 & $3.3 \mathrm{bc}$ & $6.7 \mathrm{c}$ & $6.7 \mathrm{c}$ & $100.0 \mathrm{a}$ & $33.3 \mathrm{ab}$ \\
\hline 15 & $0.0 \mathrm{c}$ & $0.0 \mathrm{c}$ & $0.0 \mathrm{c}$ & $100.0 \mathrm{a}$ & $50.0 \mathrm{a}$ \\
\hline
\end{tabular}

${ }^{\text {z}}$ Percent data were arcsine-transformed before the statistical analysis

${ }^{y}$ Mean values in columns followed by different letters are significantly different by Tukey's honest significance test at $P \leq 0.05$
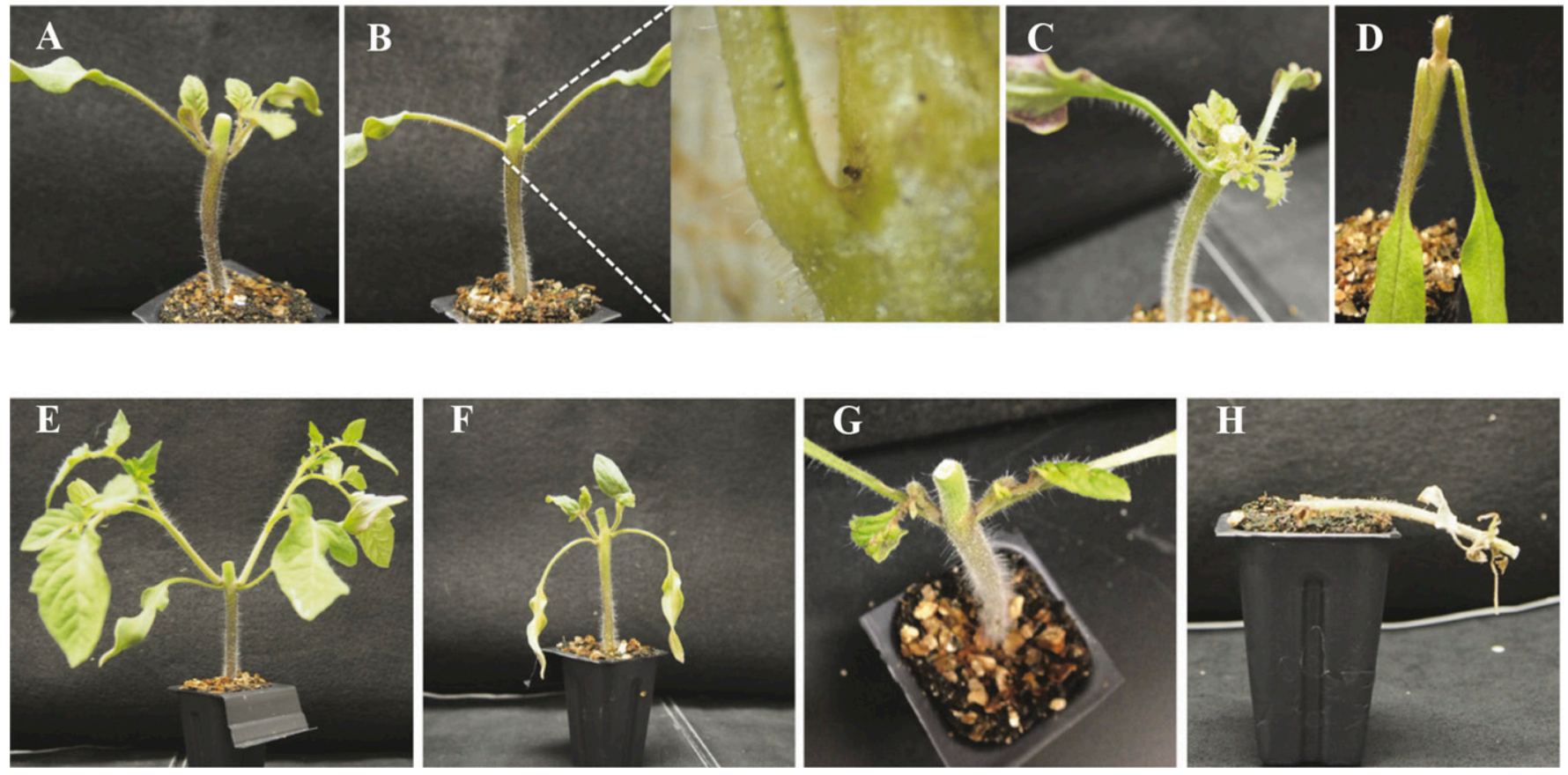

Fig. 1. Tomato seedlings with fatty alcohol at various concentrations applied to cotyledonary axillary buds [A-D (Expt. 1)] or extended cotyledonary axillary shoots [E-H (Expt. 2)]. (A) A seedling with axillary shoot extension from cotyledons $7 \mathrm{~d}$ after $0 \%$ fatty alcohol treatment. (B) A seedling with necrotic axillary buds $7 \mathrm{~d}$ after $5 \%$ fatty alcohol treatment. (C) A seedling with adventitious shoots at the stem between the cut stem end and cotyledons $22 \mathrm{~d}$ after fatty alcohol treatment. (D) A seedling with cotyledon damage caused by $\mathbf{1 5 \%}$ fatty alcohol treatment. (E) A seedling with surviving cotyledonary axillary shoots, showing growth $7 \mathrm{~d}$ after $0 \%$ fatty alcohol treatment. (F) A seedling with damaged cotyledonary axillary shoots, showing no growth $7 \mathrm{~d}$ after $4 \%$ fatty alcohol treatment. (G) Cotyledonary axillary shoots with necrotic shoot tip, leaves and petioles caused by $4 \%$ fatty alcohol treatment. $(\mathrm{H})$ A collapsed seedling caused by $\mathbf{5 \%}$ fatty alcohol treatment.

extension had the necrotic and desiccated buds in the cotyledonary axils (Fig. 1B).

Fourteen days after treatment, adventitious secondary shoots were observed in some plants with no axillary shoot extension (data not shown). At day 22 , the number of plants with adventitious shoots increased, and almost all plants with no axillary shoot extension had these adventitious shoots (data not shown). These adventitious shoots appeared to develop at either the pinched surface or the stem between the cut stem end and cotyledons, and usually they grew in clumps
(Fig. 1C), unlike the axillary shoots developed from cotyledons (Fig. 1A).

The adventitious shoot development was presumably because of the lack of active apical and axillary meristems that produce auxin. Tomato seems to produce many adventitious shoots from cut surfaces of stems when apical and axillary meristems were removed. For example, tomato in vitro explants grown on solid tissue culture medium without growth regulators regenerated 2.9-5.3 shoots on the cut surface after removing the apical and axillary meristems (PozuetaRomero et al., 2001). Also, tomato plants grown in a greenhouse reportedly regenerated many adventitious shoots from the cut surface of the stem and axillary shoots after the plants were decapitated and the axillary shoots that emerged after decapitation were excised (Harada et al., 2005; Johkan et al., 2008). If rootstock axillary buds of grafted plants were treated, the problematic adventitious shoot development would be less, as the growing scion could provide auxin to prevent adventitious shoot development. Tezuka et al. (2011) showed that adventitious shoot regeneration after decapitation was inhibited by the 
presence of axillary shoots or by application of 1-naphthaleneacetic acid in decapitated tomato plants grown in a greenhouse. However, Bausher (2011) found that rootstock shoot regrowth from cotyledons recurred even after original axillary shoots were pruned in grafted tomato plants especially when grafted above the interspecific tomato rootstock cotyledons. Therefore, adventitious shoots might occur even in grafted plants treated with high concentration of fatty alcohol. In that case, multiple applications of fatty alcohol after grafting and healing or alternative methods might be required to control axillary shoot and adventitious shoot growth from rootstock.

The degree of adventitious shoot development seems to be species specific. Commercial tomato rootstocks are generally classified in two typesintraspecific hybrid rootstocks ( $S$. lycopersicum) and interspecific rootstocks (S. lycopersicum $\times S$. habrochaites). Steinitz et al. (2006) evaluated the difference in ability for seedlings to regenerate adventitious shoots among nine species of wild tomato relatives and showed that $S$. babrochaites generated adventitious shoots at a significantly greater extent than $S$. lycopersicum when apical and axillary meristems were removed. Therefore, interspecific hybrid rootstock may have more chance to develop adventitious shoots after killing axillary shoots by fatty alcohol treatment than what we observed with 'Roma VF' (S. lycopersicum). Further study is needed to investigate possible development of rootstock adventitious shoots occurring after fatty alcohol treatment using grafted tomato plants.

Other chemical damage on the plants such as the stem scarring and the cotyledon damage (Fig. 1D) caused by fatty alcohol treatment were observed l d after treatment. Twenty-two days after treatment, the plants treated with $2 \%, 5 \%, 10 \%$, and $15 \%$ fatty alcohol had $30.0 \%, 76.7 \%$, $100 \%$, and $100 \%$ incidence of the plants exhibiting stem scarring, respectively (Table 1 ). For the $5 \%$, $10 \%$, and $15 \%$ fatty alcohol treatments, $10.0 \%, 33.3 \%$, and $50.0 \%$ of the plants had cotyledon damage, respectively. However, retaining cotyledons is not needed for tomato grafting. Also stem scarring and cotyledon damage did not seem to affect growing ability of plants after the fatty alcohol treatment in our experiment.

Expт. 2. Seven days after fatty alcohol treatment, the control plants (treated with $0 \%$ fatty alcohol) had $100 \%$ of plants with surviving cotyledonary axillary shoots (Table 2, Fig. IE). Nearly $100 \%$ of plants treated with $2 \%$ or lower concentration fatty alcohol had surviving axillary shoots, suggesting that the concentrations or dose of fatty alcohol was not enough to kill extended axillary shoot (Table 2). Fatty alcohol treatments at $4 \%$ and $5 \%$ concentrations significantly reduced axillary shoot survival and suppressed axillary shoot growth during $21 \mathrm{~d}$ after treatment, and the percentage of plants with surviving axillary shoots were $40 \%$ and $20 \%$, respectively, $21 \mathrm{~d}$ after treatment (Table 2; Fig. 1F). However, these percentages are unacceptably high for controlling cotyledonary axillary shoots from rootstock. This result indicates that fatty alcohol concentration needs to be higher than $5 \%$ to sufficiently eliminate extended cotyledonary axillary shoots. It was observed that the axillary shoots with no growth had necrotic shoot tip, leaves, and petioles (Fig. lG).

However, at $2 \%$ or greater concentrations, some plants collapsed after the treatment (Fig. $1 \mathrm{H})$. The plants treated with $0 \%, 0.5 \%$, and $1 \%$ fatty alcohol had no incidence of collapse during $21 \mathrm{~d}$ of observation (Table 2 ). For the $2 \%, 4 \%$, and $5 \%$ fatty alcohol treatments, $16.7 \%, 30.0 \%$, and $43.3 \%$ of the plants collapsed after 21 $\mathrm{d}$ (Table 2). These levels of damage are unacceptably high even though they were nonsignificantly different from that of the control except for 5\% treatment. These plants collapsed at the base of the stem, likely due to that excessive amount of fatty alcohol flowing down the stem to the substrate, causing catastrophic damage of the base of stem or the roots.

This collapse was observed in Expt. 2 but not in Expt. 1, despite that higher concentrations were applied in Expt. 1. This is probably because the volume of fatty alcohol applied to the plants in Expt. 2 was greater than that in Expt. 1. In Expt. $2,250 \mu \mathrm{L}$ of fatty alcohol emulsion was applied to cover the axillary shoot thoroughly and it was observed that fatty alcohol emulsion flowed down the stem, which was not observed in the Expt. 1 where only $5 \mu \mathrm{L}$ was applied to the target axil. From these experiments, it is suggested that the degree of chemical damage may differ depending on the dose and application method of fatty alcohol. Two percent and higher concentration fatty alcohol could cause collapse at a higher than $10 \%$ chance when fatty alcohol spills from the target shoot and flows down stem.

This experiment demonstrates the challenge of controlling already extended axillary shoots with fatty alcohol, because the effective concentration in this type of application seems to be higher than $5 \%$, what was examined in this experiment, yet is enough to collapse whole plants because of the

Table 2. Effects of fatty alcohol at various concentrations applied to extended cotyledonary axillary shoots of pinched tomato seedling on the resulting percentage of plants with surviving axillary shoot $(7,15$, or $21 \mathrm{~d}$ after treatment) and the percentage of plants collapsed ( $21 \mathrm{~d}$ after treatment) (Expt. 2$)$.

\begin{tabular}{|c|c|c|c|c|}
\hline \multirow[b]{2}{*}{ Fatty alcohol conen (\%) } & \multicolumn{3}{|c|}{ Axillary shoot survival (\%) } & \multirow[b]{2}{*}{ Collapse (\%) } \\
\hline & $7 \mathrm{~d}$ & $15 \mathrm{~d}$ & $21 \mathrm{~d}$ & \\
\hline 0 (control) & $100.0 \mathrm{a}^{\mathrm{y}}$ & $100.0 \mathrm{a}$ & $100.0 \mathrm{a}$ & $0.0 \mathrm{~b}$ \\
\hline 1 & $100.0 \mathrm{a}$ & $100.0 \mathrm{a}$ & $100.0 \mathrm{a}$ & $0.0 \mathrm{~b}$ \\
\hline 2 & $96.7 \mathrm{a}$ & $100.0 \mathrm{a}$ & $100.0 \mathrm{a}$ & $16.7 \mathrm{ab}$ \\
\hline 4 & $26.7 \mathrm{~b}$ & $36.7 \mathrm{~b}$ & $40.0 \mathrm{~b}$ & $30.0 \mathrm{ab}$ \\
\hline
\end{tabular}

${ }^{\mathrm{z}}$ Percent data were arcsine-transformed before the statistical analysis.

${ }^{y}$ Mean values in columns followed by different letters are significantly different by Tukey's honest significance test at $P \leq 0.05$. 
volume of fatty alcohol required to cover the axillary shoots. For this reason, the effective concentration of fatty alcohol has to be applied exclusively to target axillary buds without excessive fatty alcohol overflow to prevent undesirable damage. Sensitivity of true leaves and stems to fatty alcohol was also demonstrated in our separately conducted experiment examining fatty alcohol application on wide area of whole plants using an ordinary spray bottle. The result showed that spraying fatty alcohol on stems at $2 \%$ or higher or on leaves at $4 \%$ or higher concentration caused notable damage, resulting in the collapse of more than half of plants (data not shown).

Steffens et al. (1967) showed that fatty alcohol effectively damaged meristematic tissues, but caused little or no visible injury to more mature tissues in tobacco due to the protective action of surfactants. In tobacco production, commercially available fatty alcohol compounds at about 3\% to $6 \%(\mathrm{v} / \mathrm{v})$ product concentration have been used to control sucker growth after topping. The tobacco topping and sucker control are applied conventionally after the production of 18 to 22 leaves. For young tomato seedlings at three-true-leaf stage, $5 \%$ and lower concentration of fatty alcohol did not suppress cotyledonary axillary shoot growth sufficiently in pinched plants but caused true leaf damage and significant percent plant collapse despite of the inclusion of surfactant in the fatty alcohol product. This indicates that controlling cotyledonary axillary shoot growth by fatty alcohol treatment without damaging stems and true leaves is difficult possibly due to the relatively young stage of plants upon application. However, the previous reports (Maw, 1977; Tucker and Maw, 1975) showed that fatty alcohol must be applied exclusively to leaf axils, to control axillary shoot growth without injury to mature leaves in tomato at age of 5,6 , or 9 weeks, suggesting that tomato plants are possibly susceptible to this type of chemical regardless of physiological age of tissue, or that surfactants used in fatty alcohol products for tobacco might not work for protecting mature tissue of tomato. Steffens and Cathey (1969) reported that the selective action of fatty acid methyl ester and fatty alcohol as chemical pruning agents and tobacco sucker control agents depends on the class and amount of surfactant used to emulsify these chemicals. The appropriate ratio of fatty ester or alcohol to surfactants, emulsion concentration, and surfactant type may be different among plant species.

To protect mature tissues, Maw (1977) used a small brush and a felt tip marker to apply fatty alcohol only to the axillary shoots in 5 or 6 weeks of tomato plants without injury to other parts of plant. Logendra et al. (2004) used a syringe attached to a pipette to apply fatty acid methyl ester or fatty acid only to leaf axils of tomato plants after 45 or $55 \mathrm{~d}$ of seeding. In commercial propagation setting, an innovative, rapid and effective application method targeting the cotyledonary axils without excessive fatty alcohol overflow needs to be developed to avoid undesirable damage to the stems and true leaves. Application timing of fatty alcohol to the rootstock axillary buds may be critical as the effective concentration to kill the buds is highly toxic to leaves and stems. Based on our preliminary study, application after the healing and acclimatization of grafted plants seems to be less problematic than application before or during the grafting.

\section{Conclusion}

The present experiments demonstrated that target application of $10 \%$ and $15 \%$ fatty alcohol effectively suppressed cotyledonary axillary shoot extension by killing the cotyledonary axillary buds in pinched tomato seedling. Therefore, fatty alcohol might be a useful means to control axillary shoot growth from tomato rootstock cotyledons. However, to avoid undesirable damage on stems and true leaves that could occur even at a concentration as low as $2 \%$, small amount of high concentration fatty alcohol has to be applied exclusively to the target buds. Innovative application methods targeting the cotyledonary axils without excessive fatty alcohol overflow need to be developed to use fatty alcohol for controlling axillary shoot from tomato rootstock cotyledons.

\section{Literature cited}

Bausher, M.G. 2011. Grafting technique to eliminate rootstock suckering of grafted tomatoes. HortScience 46:596-598.
Cathey, H.M., G.L. Steffens, N.W. Sturt, and R.H. Zimmerman. 1966. Chemical pruning of plants. Science 153:13821383.

Colla, G. 2010. Preface to special issue of vegetable grafting. Sci. Hort. 127:91-92.

Daley, S. 2014. Chemical control of rootstock regrowth in grafted watermelon and its effects on plant growth and development. MS Thesis, Clemson Univ., Clemson, SC.

Daley, S.L. and R.L. Hassell. 2014. Fatty alcohol application to control meristematic regrowth in bottle gourd and interspecific hybrid squash rootstocks used for grafting watermelon. HortScience 49:260-264.

Harada, M., M. Oda, G. Mori, and H. Ikeda. 2005. Mass regeneration of shoots from cut surfaces of stems in tomato stock plants. J. Jpn. Soc. Hort. Sci. 74:479481 .

Johkan, M., G. Mori, K. Mitsukuri, K. Mishiba, T. Morikawa, and M. Oda. 2008. In vivo shoot regeneration promoted by shading the cut surface of the stem in tomato plants. HortScience 43:220-222.

Kubota, C., M.A. McClure, N. KokalisBurelle, M.G. Bausher, and E.N. Rosskopf. 2008. Vegetable grafting: History, use, and current technology status in North America. HortScience 43:1664-1669.

Lee, J.M., C. Kubota, S.J. Tsao, Z. Bie, P. Hoyos Echevarria, L. Morra, and M. Oda. 2010. Current status of vegetable grafting: Diffusion, grafting techniques, automation. Sci. Hort. 127:93-105.

Logendra, L.S., T.J. Gianfagna, and H.W. Janes. 2004. Preventing side shoot development with $\mathrm{C} 8 / \mathrm{Cl} 0$ fatty acids increases yield and reduces pruning time in greenhouse tomato. HortScience 39:1652-1654.

Louws, F.J., C.L. Rivard, and C. Kubota. 2010. Grafting fruiting vegetables to manage soilborne pathogens, foliar pathogens, arthropods and weeds. Sci. Hort. 127:127-146.

Maw, G.A. 1977. Aliphatic alcohols as pruning-agents for tomato side shoots. Sci. Hort. 7:43-53.

Moore, J.M. 2012. Topping and chemical sucker control programs for Georgia. In: J.M. Moore (ed.). 2013 Georgia tobacco grower's guide. 9 July 2014. <http:// www.caes.uga.edu/commodities / fieldcrops/tobacco/guide>.

Nelson, P.V. and R.K. Reid. 1971. Selectivity mechanism for the differential destruction of plant tissues by methyl decanoate emulsion. Amer. J. Bot. 58:249254 . 


\section{Preliminary and Regional Reports}

Pozueta-Romero, J., G. Houlné, L. Cañas, R. Schantz, and J. Chamarro. 2001. Enhanced regeneration of tomato and pepper seedling explants for Agrobacterium-mediated transformation. Plant Cell Tissue Organ Cult. 67:173-180.

Steffens, G.L., T.C. Tso, and D.W. Spaulding. 1967. Fatty alcohol inhibition of tobacco axillary and terminal bud growth. J. Agr. Food Chem. 15:972-975.

Steffens, G.L. and H.M. Cathey. 1969. Selection of fatty acids derivatives: Surfactant formulations for the control of plant meristems. J. Agr. Food Chem. 17:312317.

Steffens, G.L. 1980. Applied uses of growth substances-Growth inhibitors, p. 397-408. In: F. Skoog (ed.). Plant growth substances 1979. Springer-Verlag, Berlin/Heidelberg, Germany; New York, NY.

Steinitz, B., A. Amitay, V. Gaba, Y. Tabib, M. Keller, and I. Levin. 2006. A simple plant regeneration-ability assay in a range of Lycopersicon species. Plant Cell Tissue Organ Cult. 84:269-278.

Tezuka, T., M. Harada, M. Johkan, S. Yamasaki, H. Tanaka, and M. Oda. 2011. Effects of auxin and cytokinin on in vivo adventitious shoot regeneration from decapitated tomato plants. HortScience 46:1661-1665.

The University of Arizona. 2014. The Arizona meteorological network. 18 Nov. 2014. <http://ag.arizona.edu/azmet>.
Tso, T.C. 1964. Plant-growth inhibition by some fatty acids and their analogues. Nature 202:511-512.

Tso, T.C., G.L. Steffens, and M.E. Engelhaupt. 1965. Inhibition of tobacco axillary bud growth with fatty acid methyl esters. J. Agr. Food Chem. 13:78-81.

Tucker, D.J. and G.A. Maw. 1975. Chemical control of side shoots in the tomato. Sci. Hort. 3:331-338.

Wheeler, J.J., H. Seltmann, and A.G. Motten. 1991. The mode of action of fatty alcohols on leaf tissue. J. Plant Growth Regul. 10:129-137. 